\title{
Analisis Pengaruh Tekanan dan Temperatur Udara Terhadap Kinerja Turbin Gas pada Sistem PLTGU pada PT. Consolidate Electric Power Asia
}

\author{
Chandra Buana $^{1^{*}}$, Sri Suwasti ${ }^{2}$, Arman $^{3}$ dan Hafizh $^{4}$ \\ 1,2,3,4 Jurusan Teknik Mesin, Politeknik Negeri Ujung Pandang, Makassar 90245, Indonesia \\ chandra_bhuana@yahoo.com
}

\begin{abstract}
This research is a descriptive study, which aims to study the effectiveness of the GT12 Block I Gas Turbine performance in the PLTGU system at PT. Sengkang Energy. The research method is processing data using secondary data by conducting interviews and taking data from industry. The results showed that the GT12 Turbine Gas in Block I produced fluctuating power, increased between 21,940 MW to 46,106 MW and had a turbine efficiency level increased between 46.75 to $76.85 \%$. The results obtained based on the results obtained are the GT12 gas turbine engine in block I is the GT8C engine (obtained by ABB Germany) with installed power up to $60 \mathrm{MW}$, PT. Sengkang Energy consists of two total blocks producing power of $350 \mathrm{MM}$, block I of total installed power of $135 \mathrm{MW}$, the power generated has also entered into the electricity network system in South Sulawesi. The gas produced is predicted to last for the next 20 years, the gas produced in this village is also flowed into people's homes to meet the community's gas needs.
\end{abstract}

Keywords: Gas Turbine, Pressure, Temperature, Performance

\begin{abstract}
Abstrak: Penelitian ini adalah penelitian deskriptif, bertujuan untuk mengetahui keefektifan dari kinerja Turbin Gas GT12 Blok I pada sistem PLTGU pada PT. Energi Sengkang. Metode penelitian adalah mengolah data menggunakan data sekunder dengan melakukan wawancara dan mengambil data dari industri. Hasil penelitian menunjukan bahwa Turbin Gas GT12 pada Blok I menghasilkan daya yang fluktuatif, berkisar antara 21,940 MW hingga 46,106 MW dan memiliki tingkat efisinsi turbin berkisar antara 46,75 hingga 76,85\%. Hasil lain yang diperoleh berdasarkan hasil pengamatan adalah tipe mesin turbin gas GT12 pada blok I adalah mesin GT8C (diproduksi oleh ABB Jerman) dengan daya terpasang hingga 60 MW, PT. Energi Sengkang terdiri dari dua blok total menghasilkan daya sebesar $350 \mathrm{MM}$, blok I daya terpasang total sebesar $135 \mathrm{MW}$, daya yang dihasilkan juga sudah masuk kedalam sistem grid kelistrikan di Sulawesi Selatan. Gas yang dihasilkan di prediksi bisa bertahan hingga 20 tahun kedepan, gas yang dihasilkan pada desa tersebut juga dialirkan ke rumah-rumah warga untuk memenuhi kebutuhan gas masyarakat.
\end{abstract}

Kata kunci : Turbin Gas, Tekanan, Temperatur, Kinerja

\section{PENDAHULUAN}

Energi listrik merupakan salah satu energi yang memiliki peranan penting bagi kehidupan manusia. Untuk menghasilkan energi listrik, dibutuhkan unit pembangkit energi listrik. Salah satu unit pembangkit listrik yang banyak ditemukan saat ini adalah Pembangkit Listrik Tenaga Gas (PLTG). Pembangkit Listrik Tenaga Gas (PLTG) menggunakan gas alam untuk menggerakkan turbin gas yang langsung dikopel dengan generator, sehingga generator tersebut dapat menghasilkan energi listrik. Prinsip kerja ini sama dengan prinsip kerja PLTU. yang membedakan adalah pada PLTU, untuk memutar turbin digunakan uap air yang diperoleh dari mendidihkan air. Sehingga dibutuhkan suatu boiler untuk mendidihkan air tersebut. Sedangkan pada PLTG tidak ditemukan adanya boiler.

Dengan alasan peningkatan efisiensi, biasanya PLTG dikombinasikan dengan PLTU. Sehingga saat ini dikenal Pembangkit Listrik Tenaga Gas dan Uap (PLTGU).

Dalam proses kerjanya temperatur dan tekanan udara yang diperoleh dari gas alam kemudian dinaikkan pada kompressor, proses ini dinamakan proses kompressi, hal ini dimaksudkan untuk mencapai titik dimana udara/gas tersebut dapat memutar sudu-sudu turbin. 
Penggunaan turbin gas sudah berkembang pesat, sehingga penelitian untuk menganalisa dan meningkatkan kinerja turbin gas telah banyak dilakukan. Analisis performa turbin dan kompresor telah dilakukan [1] diperoleh hasil penambahan alat rekuperator dapat memperbaiki efisiensi termal siklus, efisiensi termal siklus 20,1 \% (atau nilai CER $=70,1 \%$ ), dengan laju aliran gas $69 \mathrm{~m} / \mathrm{h}$ pada putaran $19545 \mathrm{rpm}$. Studi komparasi turbin gas centaur 40 dengan Saturn 10 [2] diperoleh hasil konsumsi bahan bakar gas turbin Centaur 40 adalah 1274,184 MSCFD atau 0.0024\% dari total produksi gas, sedangkan turbin Saturn 10 membutuhkan 403,272 MSCFD atau 0.00076\% dari total produksi gas.

Pengaruh beban operasi pada kinerja turbin di PLTGU Muara Tawar Blok 1 [3] diperoleh hasil setiap 5 menit diperlukan flushing debu yang menempel pada filter, juga dibutuhkan sistem penyaring butiran air diudara sebelum masuk ke filter inlet compressor, hal ini dilakukan untuk mencegah penurunan tekanan udara yang masuk yang dapat menyebabkan penurunan kinerja turbin gas. Telah diteliti pengaruh Bypass Ratio Overall Pressure Ratio, dan Turbine Inlet Temperature terhadap specific fuel consumption (SFC) pada turbin gas [4] diperoleh hasil peningkatan nilai Bypass ratio memberi efek positif pada peningkatan efisiensi SFC, demikian pula Overall pressure ratio berdampak positif pada peningkatan efisiensi dari SFC. Pemanfaatan gas buang juga berpengaruh pada efisiensi turbin gas [5] memanfaatkan gas buang tersebut dilakukan dengan penggabungan siklus turbin gas dan turbin uap (Combine Cycle) menjadi pembangkit listrik tenaga gas dan uap (PLTGU) diperoleh hasil pemanfaatan gas buang PLTG efisiensi termal meningkat menjadi dari 45,27 \% menjadi 52,41\%.

Pengaruh water wash terhadap kinerja turbin gas telah dilakukan pada PLTG Unit 7 Paya Pasir PT. PLN sektor pembangkitan Medan [6] diperoleh hasil daya keluaran turbin gas sebelum Water Wash sebesar 38,81 MW dengan efisiensi $26,4 \%$, setelah Water Wash daya keluaran turbin gas menjadi 42,015 MW dengan efisiensi 26,85\%. Pada penelitian lainnya juga telah dilakukan analisis pengaruh turbine washing terhadap kinerja turbin uap [7] diperoleh hasil turbine washing system meningkatkan daya generator dari $53 \mathrm{MW}$ menjadi $55 \mathrm{MW}$ dalam kurun waktu 5 hari atau 96 jam.

Analisa kinerja turbin gas menggunakan generating availability data system pada PT. Pjb unit pembangkitan Muara Tawar [8] diperoleh hasil faktor ketersedian atau equivalent availability factor (EAF) tercapai pada hampir semua turbin gas tetapi tidak linier dengan capacity factor (CF) sehingga target produksi tidak tercapai dan semua turbin gas mengalami penurunan keandalan seiring waktu.

Perbandingan kinerja turbin gas sebelum dan sesudah turbine inspection juga telah dilakukan [9] diperoleh hasil terjadi kenaikan turbin gas sesudah turbine inspection, kenaikan efisiensi ini terjadi pada setiap pembebanan (load). Kenaikan efisiensi berkisar 1,6\% hingga 2,1\%, juga terjadi penurunan heat rate $134,56 \mathrm{kcal} / \mathrm{kWh}$ hingga $160,22 \mathrm{kcal} / \mathrm{kWh}$. Adapun air fuel ratio (AFR) mengalami penurunan rasio rata-rata sekitar 3,87\% hingga 4,5\%, konsumsi bahan bakar (SFC) juga mengalami penurunan rata-rata sekitar $0.016 \mathrm{~kg} / \mathrm{kWh}$ hingga $0.0265 \mathrm{~kg} / \mathrm{kWh}$.

Pada pemeliharan turbin gas terjadwal dilakukan overhaul analisis pengaruh pelaksanaan overhaul telah dilakukan di PT PLN (Persero) sektor pembangkitan PLTGU Ciligon [10] diperoleh hasil efisiensi turbin meningkat setelah overhaul, peningkatan efisiensi tertinggi sebesar $0,23 \%$ atau menghemat 15,524 MW pada beban $230 \mathrm{MW}$. Analisis kinerja turbin gas setelah overhaul juga telah dilakukan di GTG Utilitas I Pabrik PT. Petrokimia Gresik [11] diperoleh hasil efisiensi kompresor, efisiensi turbin dan efisiensi siklus meningkat $2,68 \%$, efisiensi turbin meningkat $0.9 \%$ dan efisiensi siklus meningkat $1,3 \%$.

\section{METODE PENELITIAN}

Objek penelitian ini adalah Pembangkit Listrik Tenaga Gas Uap (PLTGU) yang ada di Desa Patila, Kecamatan Pammana, Kabupaten Wajo, Sulawesi Selatan. Tipe mesin yang digunakan pada 
GT12 Blok I PT. Energi Sengkang adalah tipe mesin GT8C buatan Jerman yamg di produksi oleh ABB dengan kapasitas daya terpasang hingga $60 \mathrm{MW}$.

Metode yang digunakan dalam pengambilan data pada penelitian ini dilakukan dengan dua cara yaitu:

1. Studi Literatur : Penulis mengumpulkan data-data dengan membaca dan mempelajari berbagai literatur-literatur yang ada sesuai dengan masalah yang diteliti.

2. Wawancara (Interview) : Salah satu teknik pengumpulan data yang dilakukan oleh peneliti untuk memperoleh informasi tentang Pembangkit Listrik Tenaga Gas Uap dengan bertanya lansung pada pengelola pembangkit listrik tersebut.

Adapun teknik analisis data yang digunakan yakni analisis deskriptif. Analisa ini memberikan penjelasan atau gambaran tentang keadaan dari Pembangkit yang diteliti meliputi perhitungan efisiensi hingga perhitungan daya yang dibangkitkan.

\section{HASIL DAN PEMBAHASAN}

Sebagai contoh pengolahan data adalah dengan mengolah data yang diperoleh pada tanggal 28 Agustus 2015 pukul 09.00 WITA maka diperoleh data sebagai berikut:

- Beban : 42,5 MW

- Tempertur udara lingkungan $(\mathrm{T}): 29,33{ }^{\circ} \mathrm{C}=302,33 \mathrm{~K}$

- Tekanan udara lingkungan (P) : 1004,88 mbar : 100,488 kPa

- Tekanan udara tekan (PK 2) : 14,5 bar $=1450 \mathrm{kPa}$

- Tekanan absolute udara tekan (PK 2') : (PK $2+\mathrm{P})=1550,488 \mathrm{kPa}$

- Temperatur udara tekan (TK 2) : $458,13{ }^{\circ} \mathrm{C}=731,13 \mathrm{~K}$

- Temperatur gas buang (TAT 1) : $529,78^{\circ} \mathrm{C}=802,78 \mathrm{~K}$

- Laju aliran massa bahan bakar : $2,91 \mathrm{~kg} / \mathrm{s}$

- Nilai kalor bahan bakar (LHV) : 40324,6 kJ/kg

- Laju aliran massa udara : $220 \mathrm{~kg} / \mathrm{s}$

- $\mathrm{C}_{\mathrm{p}}$ udara : $1,005 \mathrm{~kJ} /(\mathrm{kg} . \mathrm{K})$

Maka dari data di atas dapat dihitung beberapa hal yaitu:

a) Temperature ruang bakar $\left(\mathrm{T}_{3}\right)$

$$
\begin{aligned}
& \mathrm{T}_{3}=\mathrm{TK} 2+\frac{\left(\dot{m}_{b b}\right.}{\left(\dot{m}_{u}\right.} x \frac{L H V)}{c p)} \\
& \mathrm{T}_{3}=731,13+\frac{2,91}{220} \times \frac{40324,6}{1,005} \\
& \mathrm{~T}_{3}=1261,861 \mathrm{~K}
\end{aligned}
$$

b) Temperature gas buang ideal $\left(\mathrm{T}_{4 \mathrm{~s}}\right)$

$$
\begin{aligned}
& \mathrm{T}_{4 \mathrm{~s}}=\mathrm{T}_{3}\left(\frac{P}{p K 2^{\prime}}\right)^{0,285} \\
& \mathrm{~T}_{4 \mathrm{~s}}=1261,861\left(\frac{100,488}{1550,489}\right)^{0,285} \\
& \mathrm{~T}_{4 \mathrm{~s}}=578,5362 \mathrm{~K}
\end{aligned}
$$

c) Kerja turbin ideal pada turbin gas $\left(\mathrm{W}_{\mathrm{ts}}\right)$

$\mathrm{W}_{\mathrm{ts}}=\mathrm{C}_{\mathrm{p}}\left(\mathrm{T}_{3}-\mathrm{T}_{4 \mathrm{~s}}\right)$

$\mathrm{W}_{\mathrm{ts}}=1,005(1261,861-578,5362)$ 
$\mathrm{W}_{\mathrm{ts}}=686,7413 \mathrm{~kJ} / \mathrm{kg}$

d) Kerja turbin aktual pada turbin gas $\left(\mathrm{W}_{\mathrm{t}}\right)$

$\mathrm{W}_{\mathrm{t}}=\mathrm{C}_{\mathrm{p}}\left(\mathrm{T}_{3}-\mathrm{TAT} 1\right)$

$\mathrm{W}_{\mathrm{t}}=1,005(1261,861-802,78)$

$\mathrm{W}_{\mathrm{t}}=461,3762 \mathrm{~kJ} / \mathrm{kg}$

e) Efisiensi turbin gas

$$
\begin{aligned}
\eta_{t} & =\frac{W_{t}}{W_{t s}} \\
& =\frac{461,3762}{686,7413} \\
& =67,18 \%
\end{aligned}
$$

Berdasarkan hasil perhitungan di atas maka dibuat beberapa hubungan dalam bentuk grafik yaitu sebagai berikut.

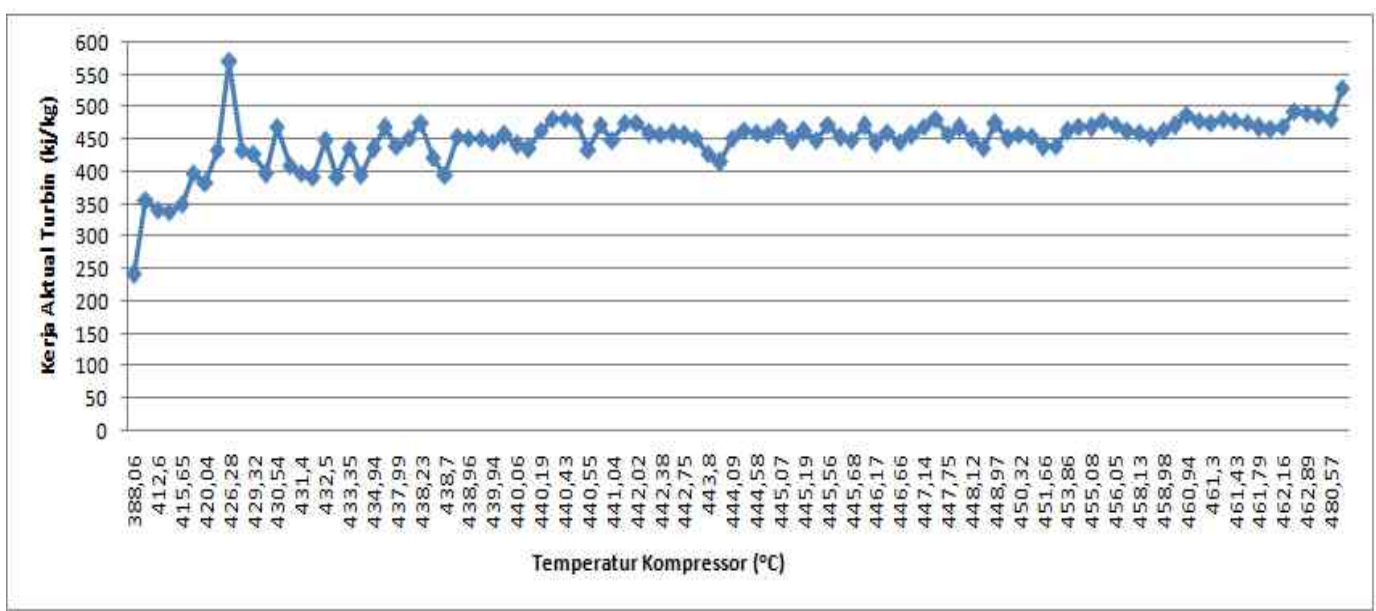

Gambar 1. Hubungan kerja aktual turbin terhadap temperatur kompressor setelah proses kompresi pada turbin gas GT12 Blok I

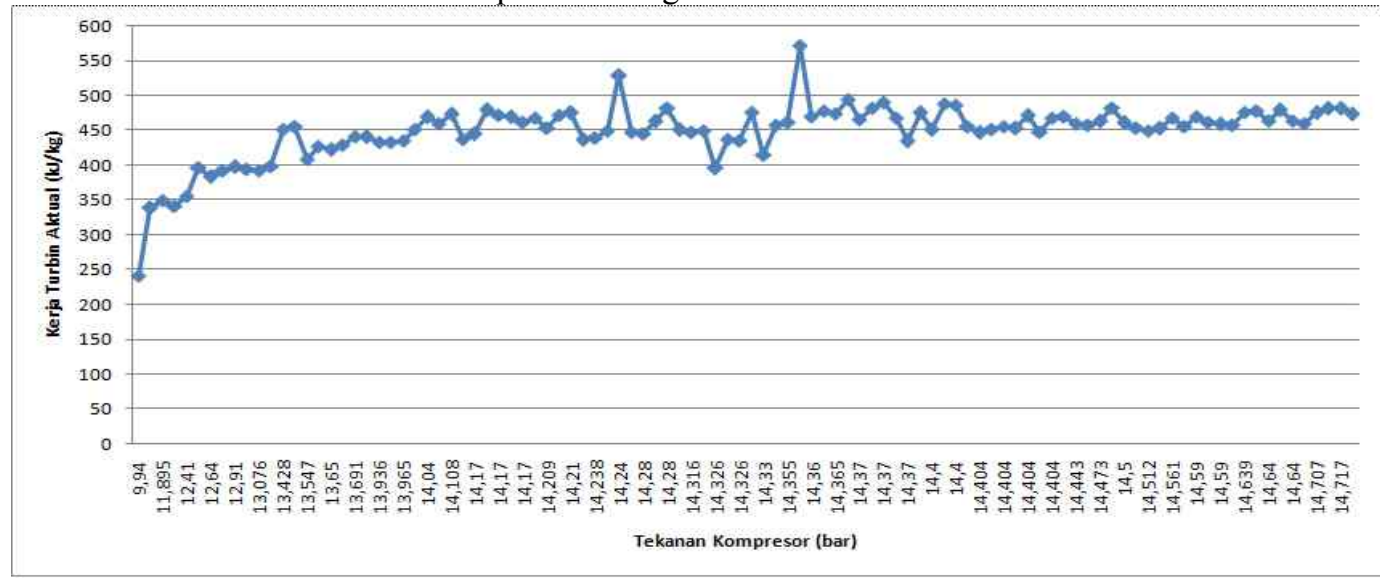

Gambar 2. Hubungan Kerja Aktual Turbin terhadap Tekanan kompressor setelah proses kompresi pada turbin gas GT12 Blok I

Berdasarkan penelitian diatas di dapatkan bahwa daya turbin gas yang dihasilkan tidak berpengaruh terhadap besarnya temperatur udara yang masuk setelah proses kompressi, itu terlihat pada gambar 1 
yang menunjukkan bahwa temperatur udara setelah kompressi sebesar $426,28^{\circ} \mathrm{C}$ menghasilkan daya sebesar 46,106 MW. Adapun untuk daya terkecil yang dihasilakn terjadi pada saat temperatur udara setelah kompressi sebesar $388,06^{\circ} \mathrm{C}$ yang menghasilkan daya turbin sebesar 21,940 MW. Untuk tekanan udara setelah kompressi sama halnya dengan temperatur udara setelah kompressi yaitu tidak berbanding lurus dengan daya yang dihasilkan, itu dapat dilihat pada gambar 2 yang menunjukkan daya yang terbesar dihasilkan pada tekanan udara setelah kompressi yaitu sebesar 14,36 bar yang menghasilkan daya sebesar 46,106 MW, yang terkecil dihasilkan pada tekanan udara setelah kompressi yaitu sebesar 9,94 bar yang menghasilkan daya sebesar 21,90 MW.

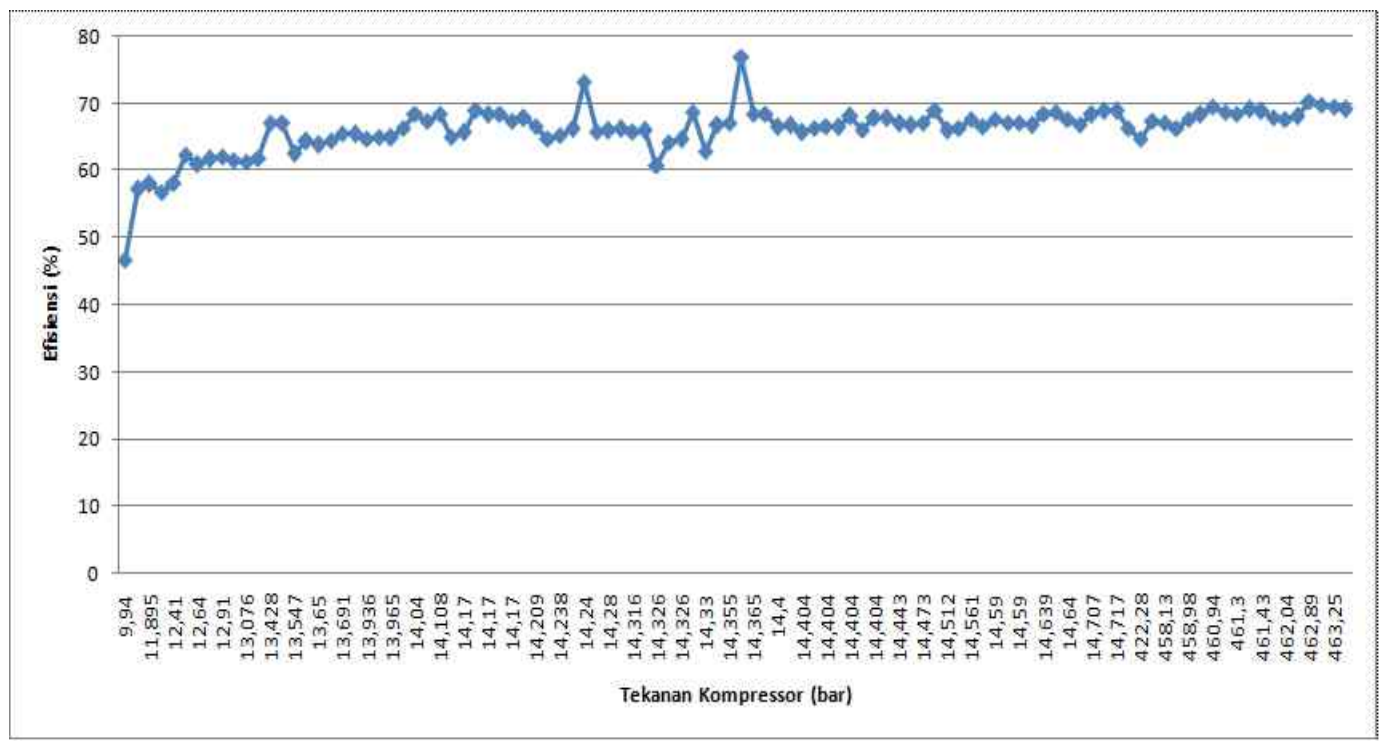

Gambar 3. Hubungan tekanan terhadap efisiensi kompressor setelah proses kompresi pada turbin gas GT12 Blok I

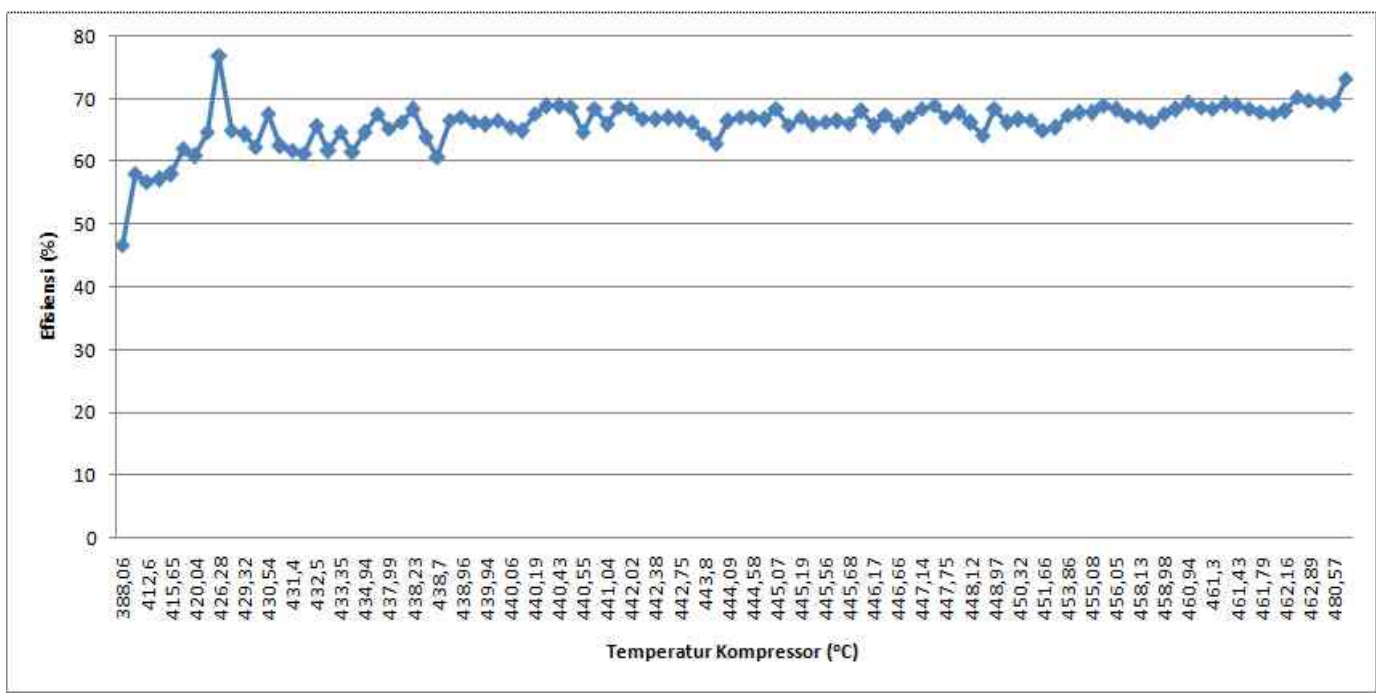

Gambar 4. Hubungan temperatur terhadap efisiensi kompressor setelah proses kompresi pada turbin gas GT12 Blok I

Berdasarkan penelitian diatas di dapatkan bahwa besarnya tekanan dan temperatur udara yang dihasilkan setelah proses kompressi tidak terlalu berpengaruh terhadap besarnya efisiensi turbin gas 
yang dihasilkan, itu dapat dilihat pada gambar 3 dan gambar 4 yang menunjukkan untuk tekanan udara setelah kompressi sebesar 14,36 bar menghasilkan efisiensi sebesar 77,68 \% sedangkan yang terkecil dihasilkan pada tekanan udara setelah kompressi sebesar 9,94 bar yang menghasilkan efisiensi turbin gas sebesar 46,75\%. Adapun untuk temperatur udara setelah kompressi menunjukkan bahwa pada temperatur $426,28^{\circ} \mathrm{C}$ yang menghasilkan efisiensi sebesar $77,68 \%$ sedangkan yang terkecil dihasilkan pada temperatur udara setelah kompressi sebesar $388,06^{\circ} \mathrm{C}$ yang mengahasilkan efisiensi turbin gas sebesar $46,75 \%$.

\section{KESIMPULAN}

Berdasarkan hasil analisa data dan pembahasan yang telah dilakukan maka dapat ditarik beberapa kesimpulan:

a. Daya turbin gas yang dihasilkan tidak berpengaruh terhadap besarnya temperatur dan tekanan udara yang masuk setelah proses kompressi, setelah kompressi diperoleh temperatur udara 426,280C dan tekanan udara 14,36 bar pada daya turbin sebesar 46,106 MW, juga diperoleh setelah kompressi temperatur udara 388,060C dan tekanan udara 9,94 bar pada daya turbin sebesar 21,940 MW.

b. Besarnya tekanan dan temperatur udara yang dihasilkan setelah proses kompressi tidak terlalu berpengaruh terhadap besarnya efisiensi turbin gas yang dihasilkan, setelah kompressi diperoleh temperatur udara 426,280C dan tekanan udara 14,36 bar pada efisiensi sebesar 77,68 $\%$, juga diperoleh setelah kompressi diperoleh temperatur udara 388,060C dan tekanan udara 9,94 bar pada efisiensi turbin gas sebesar $46,75 \%$.

\section{DAFTAR PUSTAKA}

[1] Sudadiyo, Sri. "Analisis Performa Untuk Sistem Turbin dan Kompresor." Sigma Epsilon-Buletin Ilmiah Teknologi Keselamatan Reaktor Nuklir 14.1 (2010).

[2] Muhajir, Khairul. "Studi Komparasi Unjuk Kerja Turbin Gas Centaur 40 dengan Saturn 10.", Proceeding Seminar Nasional Tahunan Teknik Mesin XI (SNTTM XI) \& Thermofluid IV, Universitas Gadjah Mada (UGM), Yogyakarta, 16-17 Oktober 2012.

[3] Naryono, Naryono, and Lukman Budiono. "Analisis Efisiensi Turbin Gas Terhadap Beban Operasi PLTGU Muara Tawar Blok 1." Jurnal Mesin Teknologi 7.2 (2013).

[4] Purnomo, Muhamad Jalu. "Pengaruh Bypass Ratio Overall Pressure Ratio, dan Turbine Inlet Temperature Terhadap SFC Pada Gas-Turbine Engine.", Jurusan Teknik Penerbangan, Sekolah Tinggi Teknologi Adisutjipto, Yogyakarta, 2014.

[5] Said, Kaudir Saputra. "Analisa Efisiensi Dan Pemanfaatan Gas Buang Turbin Gas Alsthom Pada Pembangkit Listrik Tenaga Gas Kapasitas 20 MW.”, Diss. Universitas Islam Negeri Sultan Syarif Kasim Riau, 2017.

[6] Senjaya, Febri Dwi, and Farel H. Napitupulu. "Analisa Pengaruh Water Wash Terhadap Performansi Turbin Gas Pada PLTG Unit 7 Paya Pasir PT. PLN Sektor Pembangkitaqn Medan." e-Dinamis 7.3 (2013).

[7] Anggeraini, Masrurroh, Cecep Slamet Abadi, and Deby Mardiansah. "Analisis Pengaruh Turbine Washing Terhadap Performa Turbin Uap dan Daya Pembangkitan.", Seminar Nasional Teknik Mesin, Politeknik Negeri Jakarta, 2017.

[8] Wiyono, Adri, and Bonivasius P. Ichtiarto. "Analisa Kinerja Pembangkit Turbin Gas PT Pjb Unit Pembangkitan Muara Tawar Menggunakan Generating Availability Data System." Operations Excellence 10.3: (2018) 304-320.

[9] Wijaya, Aditya Ristanu. "Analisa Perbandingan Performa Turbin Gas Sebelum Dan Sesudah Turbine Inspection Dengan Variasi Beban Di PLTGU Blok GT 3.2 Dan GT 3.3 PT. PJB UP GRESIK.”, Diss. Institut Technology Sepuluh Nopember, 2015. 
[10] Mulud, Teguh Harijono. "Analisa Efisiensi Turbin Gas Unit 1 Sebelum Dan Setelah Overhaul Combustor Inspection Di PT PLN (Persero) Sektor Pembangkitan PLTGU Cilegon." Eksergi 12.2 (2016).

[11] Island, Nadhifah Hidayati. "Kaji Performa Turbin Gas Sebelum dan Setelah Overhaul Combustion Inspection di GTG Utilitas I Pabrik PT. Petrokimia Gresik.”, Diss. Institut Teknologi Sepuluh Nopember, 2017. 